\title{
The Fifth International Outdoor Education Research Conference
}

Research in "friluftsliv" and outdoor education: Different places, critical perspectives and new possibilities!

\section{www.sdu.dk/IOERC2011, http://www.ifi.ku.dk/english}

The Fifth International Outdoor Education Research Conference will be held in Denmark, July 5. 9. 2011. The conference will be hosted by the Institute of Sports Science and Clinical

Biomechanics, University of Southern Denmark and Department of Exercise and Sport Sciences, University of Copenhagen.

The conference will build on the four previous conferences and will continue the promotion and development of an international community of researchers whose work critically examines outdoor education theory and practice.

Bringing the conference to the Nordic hemisphere and to Scandinavia introduces other places and new perspectives on research within outdoor education and might give the opportunity to experience new possibilities. Friluftsliv, or simple life in nature, represents a tradition that to some extent differ from the traditions of outdoor education, outdoor pursuits, adventure education or adventure activities. We hope and believe that interaction with different cultures and the cooperation between institutions and countries will be fruitful for the field of research within "friluftsliv" and outdoor education.

The main focus will be on works that examine different places and perceptions of place, works that present critical perspectives to myths and taken-for-granted ways of thinking or doing as well as works that point out new possibilities for researchers and practitioners in the outdoors.

The conference invites researchers from around the world to participate and contribute with works that critically examines outdoor education theory and practice.

Erik Mygind and Søren Andkjær 